\title{
Design of Cultural Products Based on Artistic Conception of Poetry
}

\author{
Shangshang Zhu \\ The Institute of Industrial Design \\ School of Art, Zhejiang University of Technology \\ Hangzhou, Zhejiang, China \\ e-mail: 756059147@qq.com
}

\author{
Zhenzhen $\mathrm{Yu}$ \\ The Institute of Industrial Design \\ School of Art, Zhejiang University of Technology \\ Hangzhou, Zhejiang, China \\ e-mail: yuzhenzhen13@126.com
}

\begin{abstract}
In the era of the experience economy, the core of designing shall be the emphasis on consumers' self-experience during usage. A good product design, therefore, shall not only express specific physical functions, but also contain a cultural connotation, reflecting the social spirit and personality ideal, Chinese poetry has a history of thousands of years. Applying the artistic conception of poetry into product design to embellish the product is an inheritance originating in the importance easterners attach to inner spirits. This study is conducted in two stages to analyze how to apply the artistic conception into product design. A mechanism for translating poetry's artistic conception to a product's artistic conception has been developed in this article, with reference to studies on cultural product design in combination with the "Image-Gestalt" in Gestalt psychology and the "transference of artistic conception" in translatology. The second stage is the creation of the design based on this translation mechanism and to discuss the feasibility of applying poetry's artistic conception into cultural product design. Finally, some suggestions have been presented for further studies.
\end{abstract}

Keywords-Poetry artistic conception; Image-Gestalt; Artistic conception translation; Cultural product

\section{INTRODUCTION}

As the hierarchy of living needs has increased in recent years, the consumption market has stepped into an era emphasizing the experience and aesthetic economy. Unique regional cultures and the construction of creative knowledge have become the core elements of a country's competitiveness. The entire world is trying to take advantage of "design" to tighten the combination between culture and creativity for the purpose of extending the aesthetic economy with cultural characteristics, especially the promotion and practice of cultural product design. Most of the cultural products, however, come out of tangible cultural assets, such as historical sites and buildings, natural landscapes, cultural landscapes, relics, etc. [7], while very few intangible cultural assets have been taken as the source of creative ideas. If "poetry" can be projected into cultural product design and be used to explain the cultural content of the product, then the intangible cultural elements can be extracted as the basis for the ideas in designing [1].

\section{LITERATURE REVIEW}

Poetry is an important part of Chinese traditional culture. The intention of the poetry-based cultural product design is to inspire the aesthetic value of the product, so as to satisfy the emotional needs of traditional cultures and enhance the product's uniqueness. This section hereby illustrates the two aspects: cultural product design and translation of the artistic conception.

\section{A. Cultural product design}

Cultural product design means to reexamine, reflect and refresh cultural elements contained in the product and to seek the spiritual-level satisfaction of the product [4]. In recent years, many attempts have been made to study cultural product design. For example, Chyuan Ho, Chi-Hsian Lin, Yi-Chun Liu [4] discussed the performance of cultural information and pointed out some key points and suggestions to design cultural products from the perspective of design information communication. Moalosi and Popovic and Hickling-Hudson [6] investigated, under the background of local cultures, the correlation mode of cultural products between designers and users by discussing social-cultural factors. Zhu Shang-shang [2] analyzed the recognition match model of consumers with respect to regional cultural image and expounded three levels of this model: outer cultural image, behavior and inner value.

Some scholars made studies on the overall framework and procedure of cultural product design. Leong and Clark [5] once made a point to study the simple framework of cultural product design, which could be divided into three levels: morphological, behavioral and psychological cultural space. Taiwan scholars Rungtai Lin [8] proposed a spatial framework for studying cultural objects. The framework is composed of three levels: outer physical/material level, mid social/behavioral level and inner intangible spiritual/ideal level, as shown in "Fig. 1". 


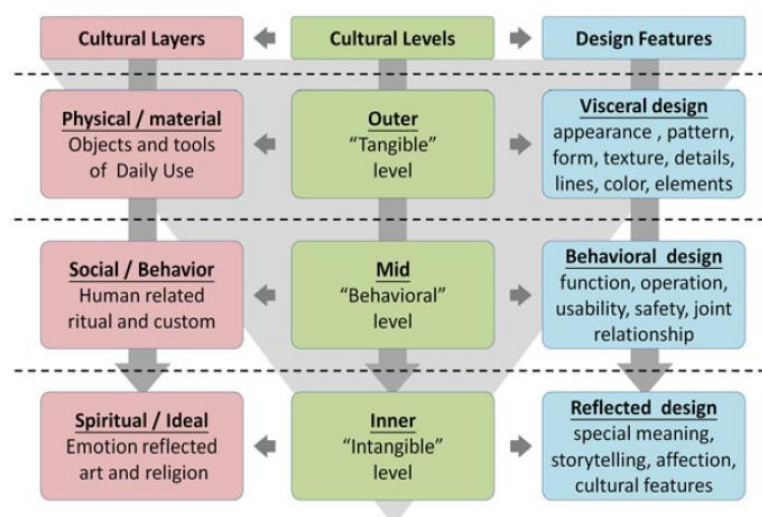

Fig.1. Three layers and levels of cultural objects and design features

Among studies on intangible cultural asserts, Wan-Li Wei [7], a Taiwan scholar, took the pattern of "two orders of signification", proposed in Roland Barthes's semiology, as the basis to construct a new procedure for designing creative cultural products. He applied intangible cultural symbols into the design of cultural products. Mo-Li Yeh, Po-Hsien Lin, ChiHsien Hsu [1] took advantage of the traditional Chinese poetic theory of shape-sprit transformation and the literary spirit of classical poetry to construct an investigative process of shapesprit transformation.

Relevant studies up to now have concentrated on discussing theoretical modes, framework-level attributes, and design strategies. A small number of these studies presented some overall procedures for cultural product design. These procedures, however, were targeted at large-scale cultures and did not favor intangible cultures over tangible cultures. The academic literature still lacks a study that can provide guidance on how to translate poetry's artistic conception into product's artistic conception. In virtue of these studies, this paper aims to develop a practical mechanism for translating from poetic artistic conception to product-oriented artistic conception, and concentrates on how to achieve such transference.

\section{B. Artistic conception translation}

The processes and methods of transfering poetry's artistic conception into a design's artistic conception are similar to those of cross-linguistic poetry translations [10]. The difference is that the poetry's artistic conception is turned into an artistic design and expressed in a product.

Poetry can have two different levels of images: an individual image and an overall image. According to Gestalt psychology, the overall image can also be called Image-G, which reflects the overall experience and is close to the artistic conception of poetry. Hence, the Image-G translation mode [9] used for poetry is also suitable for artistic conception. The Image- $\mathrm{G}$ translation mode is not an encoding-decoding process but rather it emphasizes the transference of the entire Gestalt aesthetic elements and structure [9].

The Image-G translation mode makes it possible to take concrete and practical measure to study artistic conception and clarifies the transference mechanism of artistic conceptions in poetry, as shown in Fig. 2. During the translation of the artistic conception, the translator, as a special reader, shall understand the original meaning of the poem and form corresponding psychological images. Meanwhile, the Gestalt aesthetic elements-emotion and scenario-will be formed and experienced after the structure of artistic conception has been visualized in brain and the individual image can be seen through the viewers eyes. Then, the translator shall integrate the individual image into the translated Gestalt image, where the aesthetic elements and artistic conception are reconstructed [10].

During the process of translating a poem's artistic conception into a product's artistic conception by using the mechanism for transferring poetry's artistic conception, as shown in "fig. 3", the designer will experience the poetry's artistic conception and form an aesthetic psychology, namely, acquire the aesthetic elements and individual image. The individual image is then recreated by using product designing methods. At the same time, the "emotion", "scenario" and "atmosphere" in poetry are reflected in product to reappear the artistic conception of the poetry.

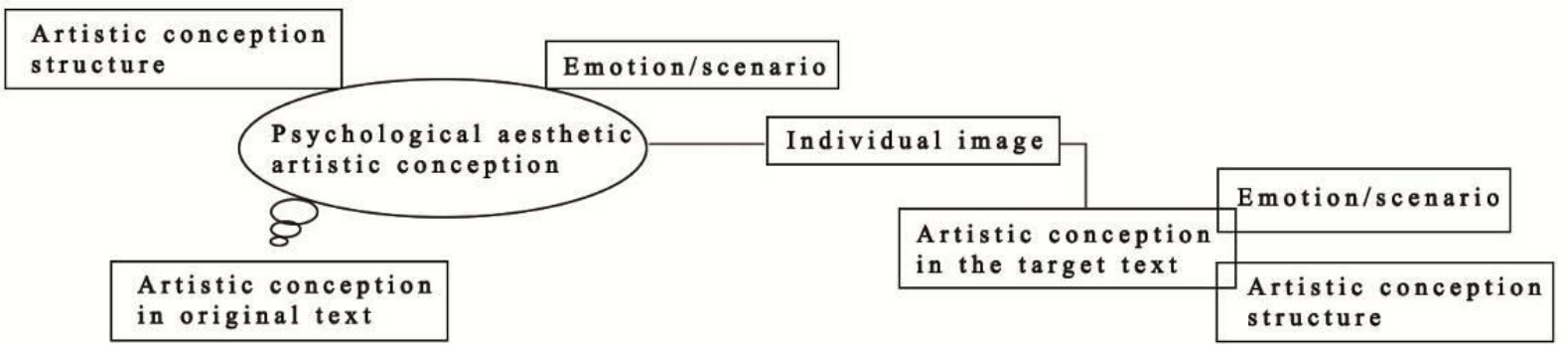

Fig.2. Artistic conception transference mode 


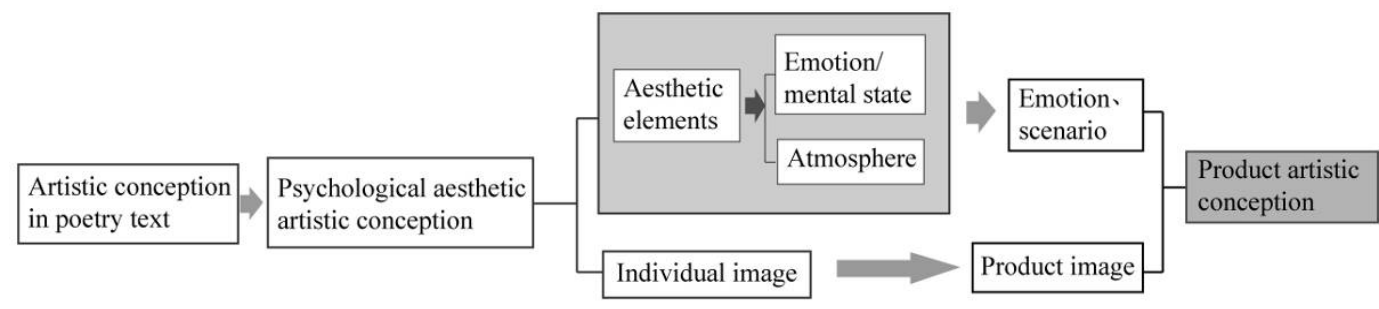

Fig.3. Poetry--product artistic conception transference mode.

\section{TRANSLATION MECHANISM FROM POETRY ARTISTIC CONCEPTION INTO PRODUCT ARTISTIC CONCEPTION}

Cultural products based on poetry's artistic conception can be designed using two methods: 1) for a given product, select an appropriate poem for the product to enable it with cultural characteristics, and; 2) for a given poem, select an appropriate product for the poem to reappear the cultural aesthetics. In this study we choose the second design procedure; select a poem first and then redesign the product.

From the studies by Taiwanese scholars Rungtai Lin [8] et al., we see that cultural product attributes [8] contain three levels: 1) outer levels, including color, texture, pattern, appearance and details; 2) mid level, including function, operation, safety, structure and usability, and; 3) inner level, including special meaning, storytelling and cultural features. These three levels of cultural product attributes are analyzed from the prospective of product's artistic conception. The outer and mid levels are mainly to reflect the image in productoriented artistic conception, while the inner level is mainly to reflect emotion and the scenario in product-oriented artistic conception.

In this paper, we developed a mechanism for translating from poetry's artistic conception to product artistic conception, based on the cultural product attribute levels proposed by
Taiwanese scholars Rungtai Lin et al. as well as on the poetry-product artistic conception transference mode turned from the Image-G translation mode, as shown in "Fig. 4".

Phase I shows the process of selecting a poem. In this process, the artistic conception of the poem shall firstly be understood and experienced to generate a psychological, aesthetic, and artistic conception, on which the poem can be based

Phase II shows the process of selecting the product. The psychological artistic conception contains an individual image and aesthetic elements, of which the former includes both the real image contained in the original poem text and the virtual image triggered from the real image. The virtual image mainly includes the emotion, scenario and atmosphere expressed in the poem. The product can be determined according to the individual image and aesthetic elements and the three levels of the product attributes. Then, the design can be carried out by seeking inspiration from the poem.

Phase III shows the process of designing the product. After the product has been determined, the three levels of the product's attributes become more specific and visual in regards to how the emotion, scenario and atmosphere will be expressed in the product. Finally, the design can be carried out based on the emotion, scenario and atmosphere. 


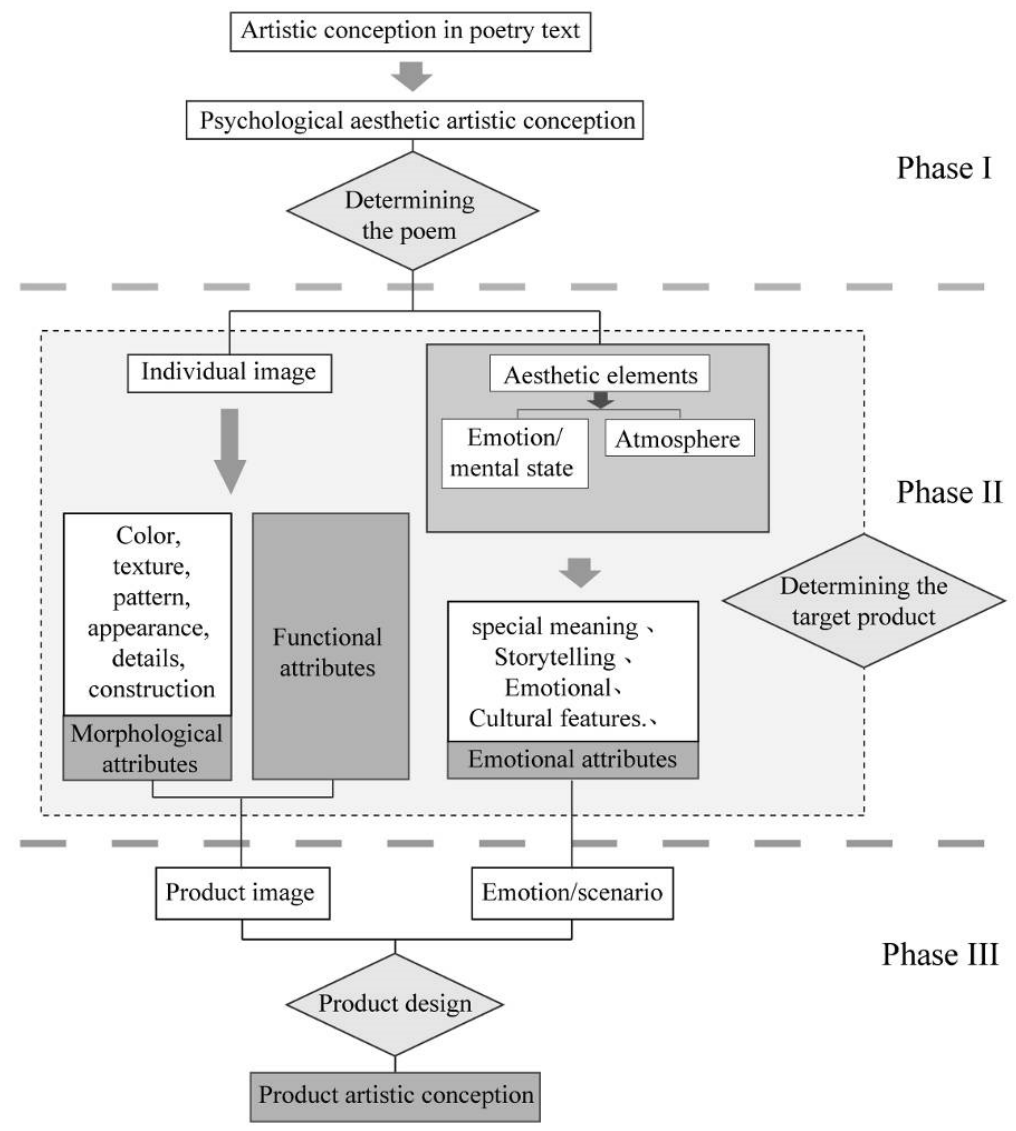

Fig.4. Poetry--product artistic conception translation mechanism.

\section{AN EXAMPLE OF APPLYING THE ARTISTIC CONCEPTION TRANSLATION MECHANISM}

In this paper, we developed a mechanism for the translation of poetry artistic conception to product artistic conception based on studies related to such transference modes. Specific steps of the artistic conception translation mechanism are hereby illustrated in a practical example shown as follows:

\section{A. Selecting the poem}

In this example, we select Snowed River by Liu Zongyuan, a poet in Tang dynasty:

Thousands of mountains can't hear the wings of the birds;

Thousands of paths can't find any footprints of the livings.

A lonely boat carries a grass rainscape behind an old man;

In the snowed river he alone fishes, fishes and fishes.

The image of the old fisherman in the poem is clear, crafted and highlighted. Both the artistic conception of the poem and the chief image--the old fisherman--can be taken as the key elements for designing.

\section{B. Determining the target product}

The aesthetic elements of this poem are the desolate and lonesome atmosphere combined with a peaceful and wild artistic conception, as shown in "Fig. 5", and the chief individual image is the "old fisherman on the lonely boat". According to the aesthetic element we can determine the product artistic conception: peace and loneliness. Such artistic conception can be reflected in usage conditions, and night is logically fit for products that meet the artistic conception. Accordingly, bedside lamp comes to mind as it can highlight the desolate and lonesome atmosphere of night. With this step, the product and usage conditions have been determined.

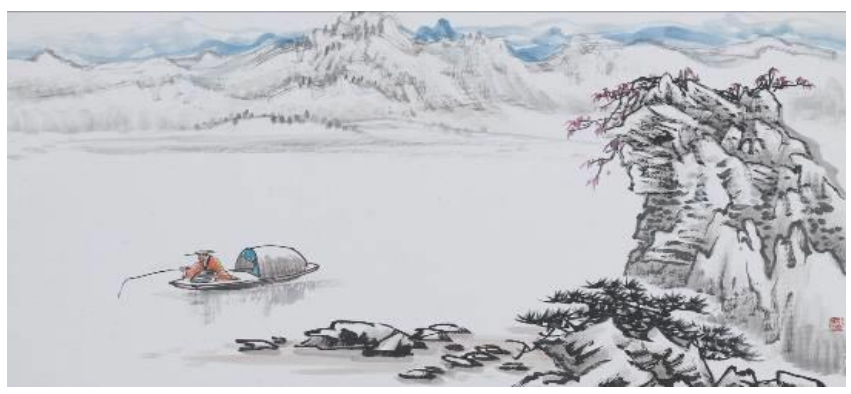

Fig.5. Artistic conception expressed in the poem.

\section{Product design}

After the product and usage conditions have been determined, the next step is to design the product. This step is mainly to extract the three levels of attributes from the product and integrate it into the usage conditions, so as to reflect the poetry's artistic conception. The chief individual image of this poem is the "old fisherman", which, after being visualized, can be taken as the design element for the shape 
of the product. In order to make the product to show the peaceful and lonely artistic conception in a better way, we select wood as the material that can give us a more approachable feeling. The sketch and Rendered picture of the design is shown in "Fig. 6".

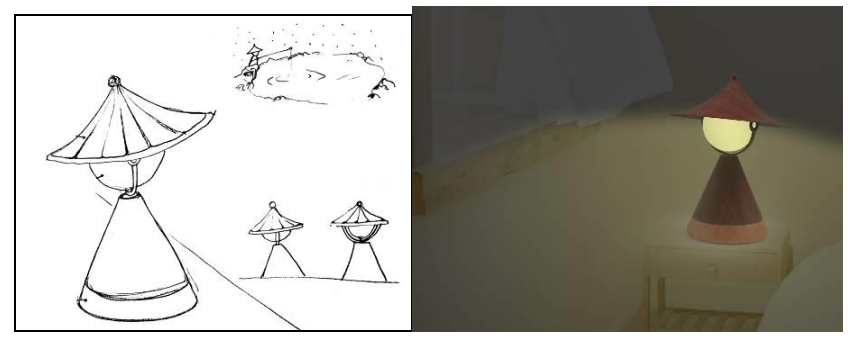

Fig.6. Sketch and Rendered picture of the product.

The three steps of the design are shown in Table I.

TABLE I. THREE STEPS OF THE DESIGN

\begin{tabular}{|c|l|l|}
\hline $\begin{array}{c}\text { Selecting the } \\
\text { poem }\end{array}$ & Snowed River & $\begin{array}{l}\text { Aesthetic elements: peaceful } \\
\text { and wild artistic conception; } \\
\text { desolate and lonesome } \\
\text { atmosphere }\end{array}$ \\
\hline $\begin{array}{c}\text { Determining the } \\
\text { product }\end{array}$ & Bedside lamp & $\begin{array}{l}\text { The lamp can highlight the } \\
\text { desolate and lonesome } \\
\text { atmosphere of night. }\end{array}$ \\
\hline Product design & $\begin{array}{l}\text { "Fisherman" } \\
\text { bedside lamp }\end{array}$ & $\begin{array}{l}\text { Shape attributes: the shape of } \\
\text { the old fisherman, wood, dark } \\
\text { color. } \\
\text { Emotional attributes: loneliness } \\
\text { and peace. }\end{array}$ \\
\hline
\end{tabular}

\section{CONCLUSIONS}

This study is an interdisciplinary and exploratory theoretical research providing guidance for practical designs and developing a mechanism for translating poetry's artistic conception to a product's artistic conception. Theories related to literature, psychology, sociology and ergonomics have been increasingly applied to the field of product design. The translation mechanism proposed in this paper is an interdisciplinary attempt.

This study finds in the practical design that: poetry's culture can be taken as a resource for the emotionalized design of products and assist designers in working out more plans that will be praised by users. The proposed translation mechanism, however, needs to be improved in the future as it is still not detailed and systematized enough. Therefore, I will continue my efforts to make this thesis more precise and systemic as well as make the translation mechanism more perfect and efficient, to ensure that it will be accepted and used by designers in practical operations, so as to work out plans that are better at supporting users' activities.

\section{REFERENCES}

[1] Mo-Li Yeh, Po-Hsien Lin, Chi-Hsien Hsu. Applying Poetic Techniques of Shape--Spirit Transformation in Cultural Creative Design [J].Journal of Design, 2011.(In Chinese).
[2] Shang-shang Zhu. Study of Regional Cultural Image in Modern Product Design[J].Packaging Engineering. 2009: (5).209-211. (In Chinese).

[3] Chun-Chih Chen, Yi-Jie L. The Application of Kano Model on Exploring the Attractive Attributes of Cultural Product Design [J].Journal of Design, 2008, 13(4): 25-41.

[4] Chyuan Ho, Chi-Hsian Lin, Yi-Chun Liu. Some Speculations on Developing Cultural Commodities [J].Journal of Design, 1996. (In Chinese).

[5] Leong, D, \& Clark, H. Culture-based Knowledge towards New Design Thinking and Practice- A dialogue. Design Issues, 2003, 19(3), 48-58.

[6] Moalosi, R., Popovic, V., \& Hickling-Hudson, A. Product Analysis based on Botswana's Postcolonial Socio-cultural Perspective. International Journal of Design, 2007, 1(2), 35-43.

[7] Wan-Li Wei. Applying Intangible Cultural Codes in Product Design Process-Using Taiwanese Religious Proverbs of South Min as an example [J].Journal of Design, 2011.(In Chinese).

[8] Chi-Hsien Hsu, Rungtai Lin. A Study on Cultural Product Design Process[J].Journal of Design, 2011.

[9] Jin Meng, Dou Feng. Transfer of imagery and artistic conception of the poetry Gestalt [J].Foreign Language Research, 2005. (In Chinese).

[10] Qiu-xia Jiang, Xiao-huai Quan. The process of Literary Translation and Image Gestalt mode [J].Chinese Translators Journal,2000. (In Chinese) 